\title{
Editorial
}

Psychopathology

\section{Personality Disorders, Functioning and Health}

\author{
Katja Bertsch Sabine C. Herpertz \\ Department of General Psychiatry, Center for Psychosocial Medicine, University of Heidelberg, Heidelberg, Germany
}

Personality disorders are conceptualized as severe and often chronic impairments in personality functioning that affect a broad range of individual and interpersonal situations [1]. Around $10 \%$ of individuals worldwide suffer from a personality disorder [2]. With prevalence rates of up to $24 \%$ in primary care [3] and more than $30 \%$ amongst psychiatric patients [4], personality disorders, as a group, range amongst the most frequent disorders treated by psychiatrists and psychotherapists [5]. One reason for the frequent usage of health services is the severity and chronicity of the impairments that cause high amounts of suffering for the affected individuals and their families. Another reason is related to the long list of comorbid mental and physical illnesses of patients with personality disorders. Therefore, a better understanding of the underlying mechanisms of personality disorders, impairments in personality functioning and comorbidity, as well as the improvement in the assessment and treatment of personality disorders remain important research topics.

In the last decade, there have been tremendous developments in the assessment and therapy of personality disorders that have also led to discussions about the validity and reliability of the concept of personality disorders in general $[6,7]$. New diagnostic and conceptual models

\section{KARGER}

() 2018 S. Karger AG, Basel

E-Mail karger@karger.com

www.karger.com/psp have been proposed which include domains of self and interpersonal functioning as key aspects of personality disorders (for instance, see the Alternative DSM-5 Model for Personality Disorders [1]). These concepts have been put forward by a very active research community that has made major progress in the understanding of underlying mechanisms of personality disorders, including deficits in affect regulation, self-worth, or interpersonal functioning.

Many of these topics have been addressed at the 15th biennial meeting of the International Society for the Study of Personality Disorders (ISSPD) in September 2017. With the title "Personality Disorders, Functioning and Health," this conference aimed at targeting not only questions related to the development of personality disorders and its neurobiological underpinnings, but also improvements in the assessment, classification, and treatment of personality disorders. Further topics concerned recent developments in functional domains as well as research addressing the comorbidity of personality disorders and other mental disorders.

We are very happy to present a selection of lectures of this conference within this special issue (Barker; Bertsch et al.; Caspar; Fossati and Somma; Herpertz et al.; Newton-Howes and Foulds; Samuel et al.; Trull) supplement- 
ed by 2 further studies that address highly relevant topics in the field of personality disorders (Daros et al.; Euler et al.).

In his summary, Barker presents the results of 2 recent studies in which the author and his colleagues investigated the role of DNA methylation as a mediator between early life adversities and mental health. Following this epigenetic and developmental perspective, alterations in the processing and regulation of emotions in patients with borderline personality disorder will be addressed by Bertsch et al. and Daros et al. While Bertsch et al. summarize recent studies on emotion processing, Daros et al. present an original study in which they compared the use of adaptive and maladaptive emotion regulation strategies between borderline patients, patients with mood and anxiety disorders, and healthy volunteers. Being one of the core symptoms of borderline personality disorder, emotion dysregulation is targeted by most of the currently available treatment programs. In the fourth paper, Herpertz et al. provide an overview of studies investigating the neurobiological mechanisms mediating treatmentrelated changes in emotion regulation in patients with borderline personality disorder.

Disturbed interpersonal functioning is one of the core features of personality disorders. This includes problems related to norm violations and socially deviant behaviors. In his article, Ruff summarizes his group's recent findings on the role of the lateral prefrontal cortex for social norm compliance and discusses their relevance for personality disorders. The following papers highlight the importance of taking narcissism (Euler et al.), conscientiousness, and openness to experiences (Samuel et al.) as well as comor- bid alcohol use disorder (Newton-Howes and Foulds) into account when treating personality disorders.

One possibility to get more information about an individual's feelings and thoughts as well as their relation to everyday life experiences is the use of ambulatory assessment, a method which is introduced and discussed in the context of personality disorders by Trull. Following this, Caspar gives an overview of new developments and challenges for the study of treatment efficacy. Finally, Fossati and Somma emphasize the need of providing support and treatment of family members of individuals with borderline personality disorder and present first empirical evidence for positive effects of different family interventions in addition to disorder-specific treatment for the patient. Together these papers provide an excellent overview of the broadness of research in the field of personality disorders with a prospect of further major progress in the understanding and treatment of these burdensome disorders in the near future.

This special issue is also the starting point for a new section within this journal which will be dedicated to personality and personality disorders. With the increasing impact experimental psychology and psychopathology have in this field, we will be happy to publish papers using innovative methods that help to understand functional impairments of the self and in interpersonal behavior. We are very happy to announce that starting in November 2018, Mark F. Lenzenweger, Distinguished Professor at the Department of Psychology, The State University of New York at Binghamton and Adjunct Professor of Psychology in Psychiatry at Weill Cornell Medical College will join Psychopathology as section editor in this field.

\section{References}

1 American Psychiatric Association: Diagnostic and Statistical Manual of Mental Disorders, ed 5. Arlington, American Psychiatric Publishing, 2013.

- Sansone RA, Sansone LA: Personality disorders: a national-based perspective on prevalence. Innov Clin Neurosci 2011;8:13-18.

3 Moran P, Jenkins R, Tylee A, Blizard R, Mann A: The prevalence of personality disorder among UK primary care attenders. Acta Psychiatr Scand 2000;102:52-57.
4 Zimmerman M, Rothschild L, Chelminski I: The prevalence of DSM-IV personality disorders in psychiatric outpatients. Am J Psychiatry 2005;162:1911-1918.

5 Zimmerman M, Chelminski I, Young D: The frequency of personality disorders in psychiatric patients. Psychiatr Clin North Am 2008; 31:405-420.
6 Herpertz SC, Huprich SK, Bohus M, Chanen A, Goodman M, Mehlum L, Moran P, Newton-Howes G, Scott L, Sharp C: The challenge of transforming the diagnostic system of personality disorders. J Pers Disord 2017;31:577589

7 Hopwood CJ, Kotov R, Krueger RF, Watson D, Widiger TA, Althoff RR, et al: The time has come for dimensional personality disorder diagnosis. Personal Ment Health 2018;12:8286. 